\title{
Adsorption of Toluene on Granular Activated Carbon
}

\author{
Kaushal Naresh Gupta, Nandagiri Jagannatha Rao, and Govind Kumar Agarwal
}

\begin{abstract}
The primary objective was to experimentally determine the performance of granular activated carbon in effectively adsorbing volatile organic compounds from inert gaseous stream under varying operating conditions. Experiments were carried out to study adsorption of toluene a volatile organic compound (VOC) on the granular activated carbon. The experiments were carried out in a fixed bed adsorption column under various operating conditions. The range of experimental variables is as follows: inlet gas concentration $(7000$ - 24775 ppm), gas flow rate $(50$ - 70 $\mathrm{ml} / \mathrm{min})$ and height of the adsorbent bed $(0.015-0.025 \mathrm{~m})$. The breakthrough curves were then drawn between ratios of outlet gas concentration to inlet gas concentration versus time for different operating conditions.
\end{abstract}

Index Terms-Adsorption, VOCs, Granular activated carbon, Toluene, Breakthrough Curve

\section{INTRODUCTION}

Rapid economic development and urban population growth have triggered a series of challenges to the endeavors of maintaining the clean air. Urban air quality is cause of public concern, largely as a result of instances of smog and health problems. New pollutants are being increasingly recognized. Air pollution sources have grown and so also the pollutants. Some of these have led to emission of some hazardous air pollutants like volatile organic compounds. Volatile Organic Compounds (VOCs) are chemicals that evaporate easily at room temperature i.e. they have high enough vapor pressure under normal conditions to significantly vaporize and enter the atmosphere. They are characterized by a very high vapor pressure, exceeding 0.5 $\mathrm{kPa}$ at $25^{\circ} \mathrm{C}$ [1]. VOCs are aliphatic and aromatic hydrocarbons, which may contain hetro-atoms, like oxygen, sulphur, nitrogen, halogens. A wide range of carbon based molecules such as aldehydes, ketones, hydrocarbons etc are VOCs. Volatile organic compounds are contributors to the formation of ozone and other photochemical oxidants leading to urban smog. Many VOCs have been identified as toxic, carcinogenic or mutagenic at concentrations levels found in urban environment [2]. VOC exposures are often associated with an odor while at other times there is no odor. Both can be harmful. Emissions of VOCs originate from breathing and loading losses from storage tanks, venting of process vessels, leaks from piping and equipment [3].There are thousands of different VOCs produced and used in our daily lives. For e.g. Benzene, Toluene, Methylene chloride, Formaldehyde,

Manuscript received August 9, 2011; revised October 1, 2011.

The authors are with the Department of Chemical Engineering, Jaypee University of Engineering \& Technology, A.B. Road, Raghogarh, Distt. :Guna (M.P) - 473226, India. Tel.: +91-7544-267310, fax: +91-7544-267011 (E-mail; kn.gupta@juet.ac.in, kaushalnaresh74@gmail.com)
Xylene, Ethylene glycol, 1,3-Butadiene etc. Approximately 235 million tons of VOCs are released per year into the atmosphere by man-made sources [4]. The subject has become important because of the impact on environment and human.

Recommended strategies for reducing organic vapors include product substitution or reformulation, thermal or catalytic incineration and activated carbon adsorption (followed by regeneration of the adsorbent and VOC and VOC recovery or catalytic incineration of the highly concentrated stream) [5]. The removal of volatile organic compounds commonly performed by adsorption is of great interest for the air quality control. At a low-concentration level, adsorption on active carbon is the most employed method for the removal of VOCs [6].The need is an adsorption process is to have a porous solid medium providing high adsorption capacity. A large surface area or large micro-pore volume can be achieved due to the porous structure of the solid. The breakthrough curve is reflective of the adsorbents performance under dynamic conditions. A relatively larger breakthrough time and gradual increase in the concentration following breakthrough are desirable.

One of the main issues is the concentration measurement of VOC in a gas-vapor mixture. Das et al. [7] assumed gas to be saturated after being passed through the column filled with the VOC liquid. Some researchers [8-9] also assumed the exit gas to be saturated with VOC at the concentration corresponding to the temperature of the bubbler. Lordgooei et al. [10] passed nitrogen gas through two fritted glass bubblers connected in series containing VOC liquid and immersed in a temperature-controlled water bath and then the exit nitrogen gas from the second bubbler was assumed to be saturated with VOC corresponding to the temperature of the bubbler. Asnin et al. [11] also prepared a gas-vapor mixture by the passage of nitrogen through a saturator containing chlorobenzene at $0^{\circ} \mathrm{C}$ and then the exit gas was assumed to be saturated. Hence by reviewing the literature it has been found that in most of the studies carried so far on the adsorption of VOCs the concentration of VOC in the gas-vapor mixture was found by assuming it as saturated gas after being passed through VOC liquid. In such techniques it is always debatable whether the vapor-gas mixture is saturated or not. In the present study the technique used for measuring the concentration of VOC in a gas-vapor mixture was by drawing a calibration curve obtained from the saturated gas-vapor mixture prepared separately in a gas collector at a particular fixed temperature.

The major objectives of this study were as follows: (1) set-up of an experimental test bench to study the adsorption phenomena for the removal of VOCs by commercially available GAC. (2) Obtain breakthrough curves under varying operating conditions such as inlet concentrations, gas flow rate and height of the adsorbent bed. 


\section{EXPERIMENTAL STUDIES}

The experiments were carried on granular activated carbon (density $400 \mathrm{~kg} / \mathrm{m}^{3}$ ) particles of diameter $0.0015 \mathrm{~m}$. The other physical properties of activated carbon were found from [12] and are listed in Table. I. The several operating conditions under which the adsorption experiments were carried out were inlet concentration of VOC, gas flow rate and adsorbent bed height. Table. II describes these conditions.

TABLE I Physical Properties of ACtivated CARBon [12]

\begin{tabular}{|l|l|l|}
\hline Parameter & Unit & Range \\
\hline BET surface area & $\mathrm{m}^{2} / \mathrm{g}$ & $1100-1200$ \\
Particle porosity & - & $0.4-0.6$ \\
Macropore volume & $\mathrm{cm}^{3} / \mathrm{g}$ & $0.2-0.5$ \\
Micropore volume & $\mathrm{cm}^{3} / \mathrm{g}$ & $0.15-0.5$ \\
& & \\
\hline
\end{tabular}

TABLE II RANGE OF EXPERIMENTAL VARIABLES

\begin{tabular}{|l|l|l|}
\hline Parameter & Unit & Range \\
\hline Inlet VOC concentration & $\mathrm{ppm}$ & $10746-24775$ \\
Gas flow rate & $\mathrm{ml} / \mathrm{min}$ & $50-70$ \\
Weight of adsorbent & $\mathrm{g}$ & $4-6.63$ \\
Bed height & $\mathrm{m}$ & $0.015-0.025$ \\
Adsorption temperature & $\mathrm{K}$ & 304 \\
\hline
\end{tabular}

\section{A. Experimental Set-up}

Figure 1 is the schematic of the experimental set-up designed and used for carrying out adsorption experiments. The set-up consists of three sections: a gas preparation section, an adsorption section, and an analytical section. In the gas preparation section, carrier gas (nitrogen in this case) is bubbled in the liquid VOC (i.e. toluene) contained in a vertical glass column $(0.7 \mathrm{~m}$ long and $0.05 \mathrm{~m}$ diameter $)$. Isothermal conditions are maintained in the column by circulating water at a fixed temperature around the column. The bubbler is a SS of $6.35 \mathrm{~mm}$ diameter tube whose bottom end is closed and the outer surface is perforated with a hole of diameter $0.08 \mathrm{~mm}$ near the bottom and nitrogen is bubbled in the toluene liquid through the hole. Part of the nitrogen gas at a measured flow rate is bubbled through the toluene liquid and another part of nitrogen is sent directly to the mixing chamber for getting the desired dilution. The resulting gas-vapor mixture from the mixing chamber is sent to the adsorption section consisting of a vertical glass column (I.D $=5 \mathrm{~cm}, \mathrm{~L}=10 \mathrm{~cm}$ ) filled with an adsorbent with provisions for the gas inlet and outlet. The effluent gas stream from the adsorption section is passed to the analytical section consisting of a gas chromatograph (MICHRO-9100, Netel (India) limited) with flame ionization detector (FID) and data station. A computer is connected to the data station to store the peak area. There is a provision of a by-pass line for measuring the inlet concentration of toluene through gas chromatograph.

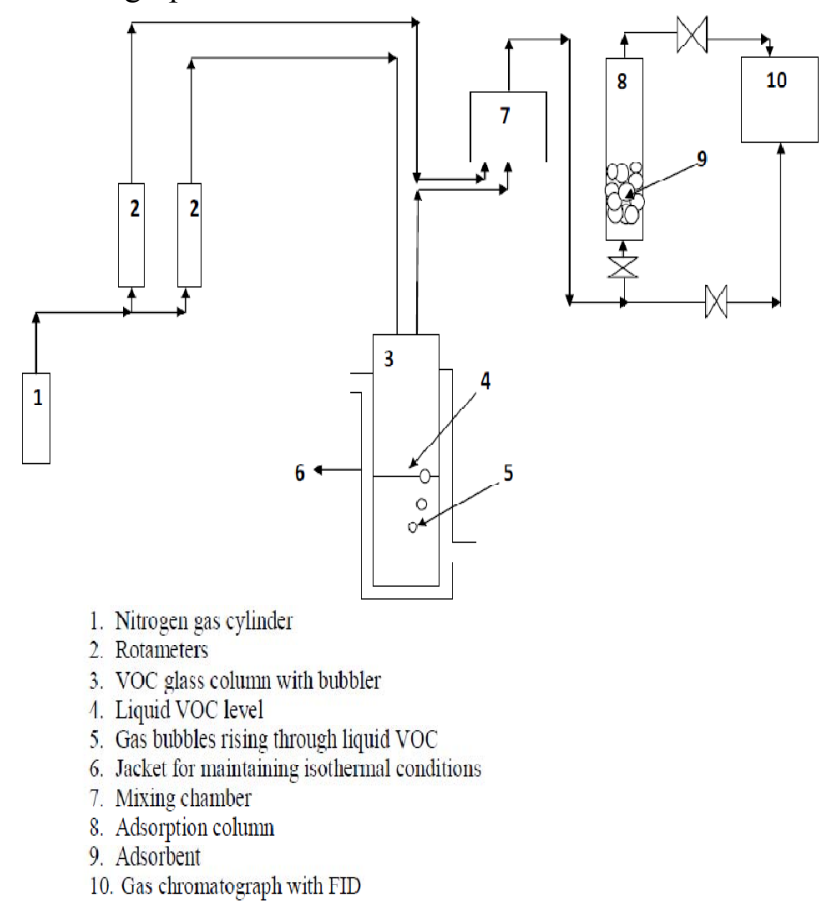

Fig. 1 Schematic diagram of the experimental set-up for VOC adsorption

\section{B. Experimental Procedure}

A calibration curve is drawn for measuring the concentration of toluene vapor in a gas-vapor mixture. First a saturated mixture of gas containing toluene vapor is prepared. It is prepared in a gas collector which is partially filled with toluene liquid and then purged with nitrogen gas to remove last traces of air. Then it is kept in an oven maintained at a constant temperature of $313 \mathrm{~K}$ for 5-6 hours so that nitrogen gas in the vapor space gets saturated with toluene vapor. Then different volumes of samples are collected through septum fitted in gas collector with a gas-tight syringe from a vapor space and inserted it in a gas chromatograph. A calibration curve shown in Figure 2 is then drawn between log of number of moles of toluene in the sample and log of area under the curve obtained from the gas chromatograph to get a straight line. This calibration curve is used further in this study for finding out the concentration of toluene in unknown gas-vapor mixture.

Prior to start of the experiments the glass column was filled with a VOC liquid up to a certain height for getting the desired concentration of VOC in a gas-vapor mixture. Water was circulated at a fixed temperature around the column and a sufficient time was given ( 1 hour) to attain the required temperature. The weighed amount of granular activated carbon was placed into the adsorption column and is supported by glass wool from both sides to avoid any carryover of adsorbent particles. Nitrogen gas at a measured flow rate is bubbled through VOC liquid and also it was sent directly to the mixing chamber for dilution at a fixed flow rate. The concentration of the inlet gaseous mixture is measured by gas chromatograph prior to the start of the adsorption process. It takes around $3-4$ hours for the inlet gas to reach the steady state and then this gaseous mixture was allowed to pass through the adsorption column. As the adsorption process is started, the transient concentrations of exit gas from the adsorption column (breakthrough data) are monitored and measured by gas chromatograph. 


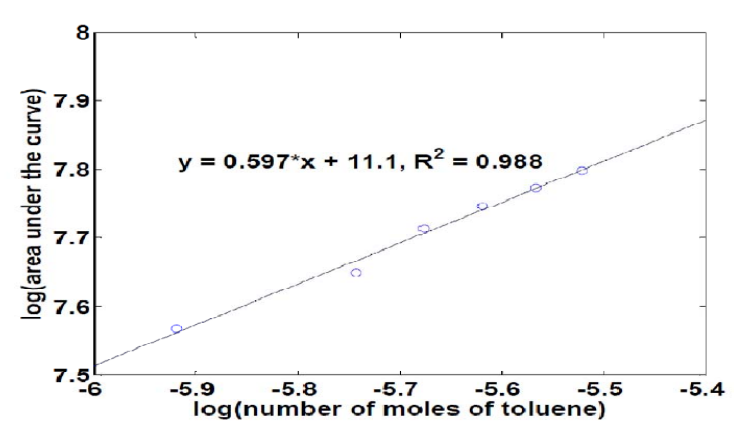

Fig. 2 Calibration curve for finding concentration of toluene in gas phase.

\section{RESUlTS AND DiscUSSION}

Here breakthrough curves are drawn for different operating conditions. In each case breakpoint time is found out which is defined as time taken for the effluent concentration to reach $5 \%$ of the inlet concentration.

\section{A. Effect of Bed height}

Figure 3 shows the outlet effluent concentration as a function of time for different bed heights. At any given bed height outlet concentration increases with increase in time after breakpoint is reached. For any time increase in bed height results in decrease in outlet concentration. The breakpoint time increases with increase in bed height. Typically an increase in bed height from $0.015 \mathrm{~m}$ to $0.025 \mathrm{~m}$ results in an increase in breakpoint time over two times. The increase in the breakthrough time with increase in the bed height as observed from Figure 3 can be explained in terms of the total amount of adsorbent present in the bed. With increase in the bed height which implies more amount of adsorbent under identical flow rates and inlet gas concentrations the bed will get saturated in a longer time.

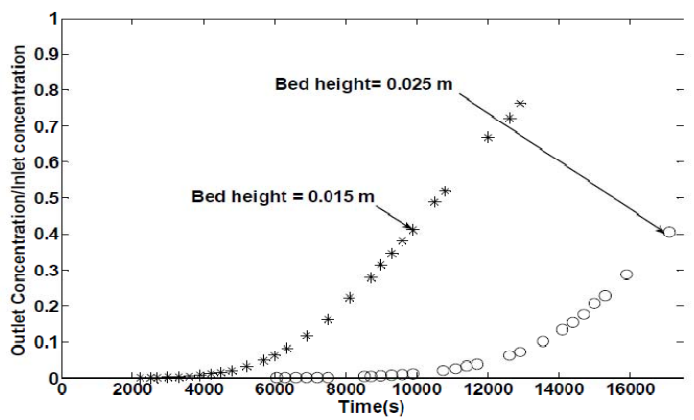

Fig. 3 Effect of bed height on breakthrough curve (flow rate $=70 \mathrm{ml} / \mathrm{min}$, Inlet concentration $=11500 \mathrm{ppm}$ )

\section{B. Effect of Inlet concentration}

Figure 4 shows the outlet effluent concentration as a function of time for different inlet concentration of VOCs. At any given inlet concentration the outlet concentration increases with increase in time after breakpoint is reached. For any time an increase in inlet concentration results in increase in outlet concentration. The breakpoint time decreases with increase in inlet concentration. An increase in inlet concentration from 7000 to $11500 \mathrm{ppm}$ results in decrease in breakpoint time from 6205 to 5468 seconds. The increase in the breakthrough and total adsorption times with the decrease in inlet concentration levels as observed from Figure 4 can be explained in terms of the total amount of VOC. With decrease in the inlet concentration under identical flow rates, the total amount of VOC (moles) entering the macro-pores of the adsorbent is less. Therefore, the saturation of the adsorbent bed is delayed and occurs in relatively longer time.

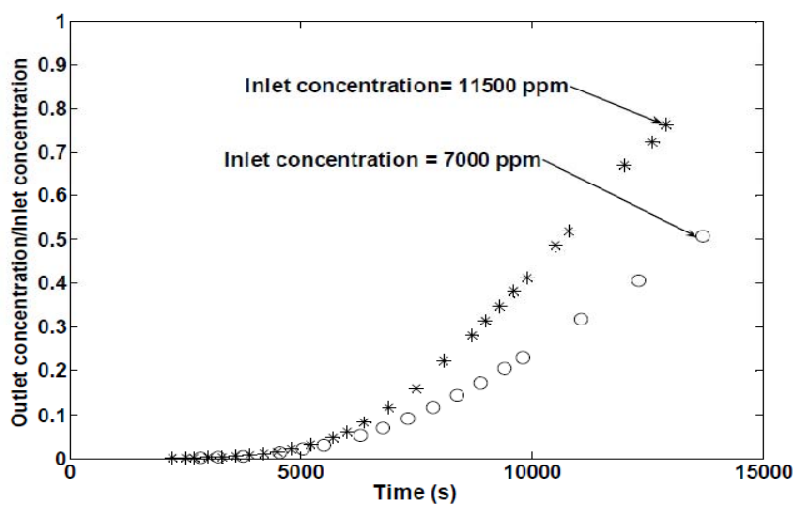

Fig. 4 Effect of inlet concentration on breakthrough curve (flow rate $=70$ $\mathrm{ml} / \mathrm{min}$, bed height $=0.015 \mathrm{~m}$, weight of the adsorbent $=4 \mathrm{~g}$ )

\section{Effect of flow rate and Inlet concentration}

The effect of flow rate at constant inlet concentration could not be found out separately because to maintain a constant inlet concentration, liquid level in the glass column had to be changed which required hit and trial method. Hence the combined effect of flow rate and inlet adsorbate concentration on breakthrough curve has been found out. So to find their individual effect, modeling and simulation of fixed bed adsorption column is required.

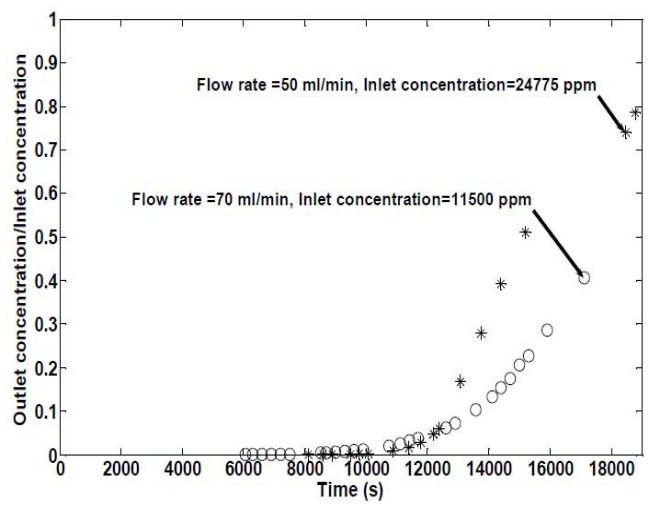

Fig. 5 Effect of flow rate and inlet concentration on breakthrough curve (bed height $=0.025 \mathrm{~m}$, weight of the adsorbent $=6.63 \mathrm{~g}$ ).

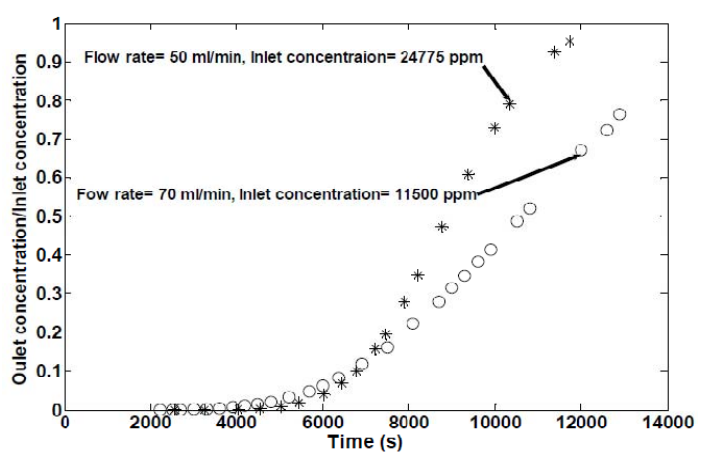

Fig. 6 Effect of flow rate and inlet concentration on breakthrough curve (bed height $=0.015 \mathrm{~m}$, weight of the adsorbent $=4 \mathrm{~g}$ ).

Figure 5 shows the outlet effluent concentration as a function of time for different inlet concentration and flow rate. At any given flow rate and inlet concentration, the outlet concentration increases with increase in time after breakpoint time is reached. The breakpoint time is slightly more when the flow rate is decreased from 70 to $50 \mathrm{ml} / \mathrm{min}$ and the inlet 
concentration is increased from 11500 to $24775 \mathrm{ppm}$. But after breakpoint decrease in flow rate and increase in inlet concentration results in increase in outlet concentration. Similar breakthrough curves are shown in Figure. 6 for a bed height of $0.015 \mathrm{~m}$. The decrease in total adsorption time with decrease in flow rate and increase in inlet concentration as observed from Figure 5 and Figure 6 is primarily due to the more dominant role played by the increase in concentration as compared to the decrease in flow rate.

\section{CONCLUSIONS}

The adsorption of toluene on granular activated carbon has been studied for various operating parameters. The breakpoint time increased with increase in bed height and it decreased with increase in inlet concentration. In all the cases it has been found out that it is not only the concentration difference which is controlling the overall adsorption process but there are other some other factors also which controlled the overall adsorption process. Hence there is a need to develop mathematical model for predicting other breakthrough curves. The effect of flow rate on breakthrough curve could not be found out separately. Hence modeling and simulation of fixed bed adsorption column was required to predict the breakthrough curves. So further we will do modeling and simulation of the present fixed bed adsorption column to predict breakthrough curves.

\section{REFERENCES}

[1] M. Magureanu, N.B. Mandache, P. Eloy, E.M. Gaigneaux, V.I. Parvulescu, "Plasma-assisted catalysis for volatile organic compounds abatement", Applied catalysis B: Environmental, 61, 2005, pp.12-20.

[2] A. Srivastava, "Source apportionment of ambient VOCs in Mumbai city", Atmospheric Environment, 38, 2004, pp. 6829-43.

[3] F.I. Khan, A.K. Ghoshal, "Removal of volatile organic compounds from polluted air", Journal of Loss Prevention in the Process Industries, 13, 2000, pp. 527-45.

[4] A.O. Malley, B.K. Hodnett, "The influence of volatile organic compound structure on conditions required for total oxidation", Catalysis Today, 54, 1999, pp. 31-38.

[5] A.B. Fuertes, G. Marban, D.M. Nevskaia, "Adsorption of volatile organic compounds by means of activated carbon fibre-based monoliths", Carbon, 41, 2003, pp. 87-96.

[6] G. Marban, T.V. Solis, A. B. Fuertes, "Modeling the breakthrough behavior of an activated carbon fiber monolith in n-butane adsorption from diluted streams", Chemical Engineering Science, 61, 2006, pp. 4762-72.

[7] D. Das, V. Gaur, N. Verma, "Removal of volatile organic compound by activated carbon fiber", Carbon, 42, 2004, pp.2949-62.

[8] P. Dwivedi, V. Gaur, A. Sharma, Verma, "Comparative study of removal of volatile organic compounds by cryogenic condensation and adsorption by activated carbon fiber", Separation and Purification Technology, 39, 2004, pp. 23-37.

[9] V.Gaur, A. Sharma, N.Verma, "Catalytic oxidation of toluene and $\mathrm{m}$-xylene by activated carbon fiber impregnated with transition metals", Carbon, 43, 2005, pp.3041-53.

[10] M. Lordgooei, K.R. Carmichael, T.W. Kelly, M. J. Rood, S. M. Larson, "Activated carbon cloth adsorption-cryogenic system to recover toxic volatile organic compounds",Gas. Sep. Purif., 10, 1996, pp.123-30.

[11] L.Asnin, A.Fedorov, D.Yakusheva, "Adsorption of chlorobenzene vapor on $\mathrm{V}_{2} \mathrm{O}_{5} / \mathrm{Al}_{2} \mathrm{O}_{3}$ catalyst under dynamic conditions", Adsorption, 14, 2008, pp.771-79.

[12] D.M. Ruthven, "Principles of adsorption and adsorption processes", John Wiley \& Sons, New York, 1984, pp. 8. 